\title{
Is There a Relationship between Endotheline-1, Vascular Cell Adhesion Molecule-1 and the Arterial Hypotension Observed during Spinal Anesthesia?
}

\author{
J. F. Nnang Essone1,2, K. Nzé Pascal ${ }^{3}$, G. Edjo Nkhilli, N. Ekegue1,2, Diaw Mor ${ }^{5}$, \\ C. P. Akagha Kondé6, P. Nzoghe Nguéma², E. Anyunzok ${ }^{7}$, E. R. Obame², \\ C. Allognon ${ }^{6}$, B. Nguéma Asseko ${ }^{8}$, F. Ovono Abessolo9 ${ }^{9}$, E. Ngou Milama ${ }^{9}$
}

${ }^{1}$ Department of Physiology, Faculty of Medicine and Health Sciences of Libreville (USS), Libreville, Gabon ${ }^{2}$ Department of Anesthesia and Emergency Resuscitation, The University Hospital of Owendo, Libreville, Gabon ${ }^{3}$ Department of Anesthesia and Emergency Resuscitation, The Mother Child University Hospital Center, Libreville, Gabon ${ }^{4}$ Department of Anesthesia and Resuscitation, The Army Instruction Hospital, Libreville, Gabon ${ }^{5}$ Laboratory of Biology and Physiological Functional Explorations, UCAD, Dakar, Senegal ${ }^{6}$ Department of Medicine, The University Hospital of Libreville, Libreville, Gabon ${ }^{7}$ Department of Epidemiology, Biostatistics and Medical Mathematics, USS, Libreville, Gabon ${ }^{8}$ Department of Surgery, The University Hospital of Libreville, Libreville, Gabon ${ }^{9}$ Department of Chemistry-Biochemistry, Faculty of Medicine and Health Sciences, USS, Libreville, Gabon Email: jfnnang@gmail.com

How to cite this paper: Nnang Essone, J.F., Pascal, K.N., Nkhilli, G.E., Ekegue, N., Mor, D., Kondé, C.P.A., Nguéma, P.N., Anyunzok, E., Obame, E.R., Allognon, C., Asseko, B.N., Abessolo, F.O. and Milama, E.N. (2021) Is There a Relationship between Endotheline-1, Vascular Cell Adhesion Molecule-1 and the Arterial Hypotension Observed during Spinal Anesthesia? Journal of Biosciences and Medicines, 9, 64-85. https://doi.org/10.4236/jbm.2021.91006

Received: December 2, 2020 Accepted: January 23, 2021 Published: January 26, 2021

\begin{abstract}
Introduction: The involvement of the endothelial dysfunction (ED) in arterial hypotension (AHPT) post of spinal anesthesia (SA) has not been established. Objective: To determine if there is a relationship between ED and AHPT observed during the 1 st 15 minutes after SA. Population and Methods: The study concerned 40 people who were to benefit from a programmed herniorrhaphy under SA and 40 controls $\left(\mathrm{SA}^{-}\right)$. The correlations between mean plasma concentrations of endothelin-1 (CmET-1, pg/ml) and Vascular Cell Adhesion Molecule-1 (CmVCAM-1, pg/ml) taken from $\mathrm{SA}^{+}$ one hour before (H0), then 15 minutes after the SA (H15) and the mean arterial pression (AMP, $\mathrm{mmHg}$ ) with heart rate $(\mathrm{bpm})$ were analyzed $(\mathrm{p}<5 \%)$. Results: CmET-1 and CmVCAM-1 of SA- were 1.07 and 3.34, respectively, compared to $1.12(\mathrm{p}=0.735)$ and $3.57(\mathrm{p}=0.862)$ in $\mathrm{SA}^{+}$at $\mathrm{H} 0$ and H15. In $\mathrm{SA}^{+}$, at H15, CmET-1 was $1.13(\mathrm{p}=0.823)$ and CmVCAM-1 was $3.57(\mathrm{p}=$ 0.257). In $\mathrm{SA}^{-}$, a negative correlation existed between CmET-1 and CmVCAM-1 $(\mathrm{r}=-0.438 ; \mathrm{p}=0.005)$. Conversely, in $\mathrm{SA}^{+}$, whether at $\mathrm{H} 0(\mathrm{r}=$ $-0.31 ; \mathrm{p}=0.051)$ or at $\mathrm{H} 15(\mathrm{r}=0.024 ; \mathrm{p}=0.883)$, no correlation existed be-
\end{abstract}


Copyright $\odot 2021$ by author(s) and Scientific Research Publishing Inc. This work is licensed under the Creative Commons Attribution International License (CC BY 4.0).

http://creativecommons.org/licenses/by/4.0/ (c) (i) Open Access tween CmET-1 and CmVCAM-1, nor between MAP and ED markers ( $\mathrm{r}=$ $0.111 ; p=0.325)$. Conclusion: These results show that there is no relationship between the AHPT which occurs during the first fifteen minutes post SA, CmVCAM-1 and CmET-1. Moreover, these data suggest that ED is not involved in AHPT post SA.

\section{Keywords}

Endothelin-1, VCAM-1, Hypotension, Endothelial, Dysfunction, Spinal, Anesthesia

\section{Introduction}

The vascular endothelium has several functions, one of which is the regulation of blood pressure [1]-[6]. This regulation takes place through the secretion of vasoactive substances [1]-[6]. Thus, any disturbance affecting the barometric balance and the histological integrity of the endothelium causes its dysfunction [1] [4] [5] [6] [7]. This endothelial dysfunction (ED) is characterized by a modification of the balance between vasodilator, anti-mitotic, anti-thrombogenic and anti-adhesive substances, in favor of those known as vasoconstrictors, pro thrombogenes, pro adhesives and proliferatives [7] [8] [9]. Some of therapeutic technics such as spinal anesthesia (SA) as well as conditions of a medical or surgical nature, in varying degrees of their development can be responsible for ED [10] [11] [12] [13]. Spinal anesthesia (SA) is an anesthesia technic that involves the intra thecal injection of locoregional anesthetic [14] [15]. When performed as part of sub umbilical surgery, it causes blockage of the vegetative system in favor of the para sympathetic system [14] [15] [16]. This blockage would result in the installation of arterial hypotension, whose link with ED has not yet been clearly established [10]-[16]. On a human scale, the evaluation of endothelial dysfunction is done by non-invasive methods, but also biological, as endothelin-1 (ET-1) and vascular cell adhesion molecule-1 (VCAM-1) [1]-[10] [17]-[42]. Our hypothesis is that endothelial ED, like sympathetic paralysis, would be involved in the onset of low blood pressure observed during the first fifteen minutes after SA. To confirm this hypothesis, we monitored mean arterial pressure, as well as heart rate, assayed plasma markers of ED, and analyzed their correlations in patients before and 15 minutes after intra spinal administration of a loco regional anesthetic.

\section{Population and Methods}

\subsection{Population}

This was an observational, cross-sectional, case-control type survey carried out in Libreville (Gabon). Patient recruitment was multi-center. It was carried out within the physiological function exploration departments of the University 
Hospital of Owendo (CHUO), surgery and anesthesia-resuscitation of the University Hospital of Libreville (CHUL). The biological assays were carried out in the biochemistry laboratory of the faculty of medicine. The study population was divided into two groups. The first consisted of people who had to undergo a spinal anesthesia indicated before a programmed herniorrhaphy (Case, $\mathrm{RA}^{+}$). The second consisted of volunteers, free from any medico-surgical disease, and having socio-demographic criteria similar to those of the patients (Controls, $\mathrm{RA}^{-}$). This study was conducted in accordance with the medical ethics recommendations on the use of living things according to the declaration of Helsinki [43].

\subsubsection{Inclusion Criteria}

To be included, patients $\left(\mathrm{RA}^{+}\right)$, as well as controls $\left(\mathrm{RA}^{-}\right)$had to be male, and aged between 25 and 65 years. In addition, only those who consent and who have benefited from a clinical evaluation at the CHUO (general examination, cardiovascular, abdominal with hernial orifices) and para clinical (blood count, coagulation, uremia, glycemia, creatinine, electrocardiogram, radiography thorax of the front, retro viral serology, assay of endothelial markers) had been recruited.

\subsubsection{Non-Inclusion Criteria}

During the present survey, we did not include all people suffering from a complicated inguinal hernia, or any other pathologies of a medical or surgical nature, acute or chronic (medical and surgical emergencies, HIV infection, diabetes, hypertension blood pressure, sickle cell anemia, renal failure, neoplasia, liver disease, respiratory failure, heart failure). Likewise, subjects who are obesity, enolo-tobacco, or undergoing treatments likely to modify endothelial function were not selected [1]-[10]. In addition, in $\mathrm{RA}^{+}$, during the 15 minutes following the SA, any variation in a hemodynamic parameter of more than $20 \%$ compared to that taken preoperatively (mean arterial pressure and/or heart rate) and requiring specific therapy (vascular filling, vasoactive amines) was an exclusion factor [14] [15] [16] [44]-[49].

\subsection{Method of Study}

\subsubsection{Recruitment of $\mathrm{RA}^{+}$}

Once the diagnosis of uncomplicated inguinal hernia [50] [51] [52] [53] and the indication for operation made by the surgeon, recruitment was done consecutively in the consultation room for physiological functional explorations. The patients underwent a clinical examination (questioning, general examination, cardiovascular examination with measurement of hemodynamic parameters). At the end of this assessment, those who met the inclusion criteria were informed of the anesthesia technique and the survey details. Subsequently, as soon as the consent was obtained, an appointment was made for them at the biochemical laboratory of the faculty of medicine for the biological assays. 


\subsubsection{Recruitment of $\mathrm{RA}^{-}$}

It was carried out consecutively, on a voluntary basis, among the general population. Once consent was obtained, each control was matched to a patient by age. Then, an appointment was given to each of them at the CHUO. On the agreed date, the latter benefited from a clinical and para clinical evaluation similar to that of the patients and a sample for the biological assays. Controls were parents of patients, healthcare professionals and medical students. During the study period, 120 people meeting the eligibility criteria were identified, including $60 \mathrm{pa}$ tients $\left(\mathrm{RA}^{+}\right)$and 60 controls $\left(\mathrm{RA}^{-}\right)$. Of the $60 \mathrm{RA}^{+}$recorded, 6 had non-inclusion criteria and 14 were excluded due to arterial hypotension post spinal anesthesia requiring hemodynamic support $(n=4)$, refusal to participate $(n=4)$ and absence presentation on the scheduled day of surgery $(n=6)$. The population of $\mathrm{RA}^{+}$definitively retained was 40 people. Among the 60 selected controls, 40 were included and 20 were excluded for refusal of sampling $(\mathrm{n}=17)$ and arterial hypertension discovered during recruitment $(n=3)$. A total of 80 people participated in the study (Figure 1).

The parameters collected were age (in years), mean arterial pressure in millimeters of mercury (MAP, mmHg), and heart rate in beats per minute (HR, $\mathrm{bpm}$ ). Thus, during the first 15 minutes after spine anesthesia, all changes in hemodynamic parameters (pre-operative MAP and FC) between 10\% and 20\% of the control value were considered significant. Moreover, it was considered normal, a value of the MAP between $60-90 \mathrm{mmHg}$, and that of the HR between $60-100 \mathrm{bpm}$ [54]. At the surgical level, the data recorded were the type (inguino scrotal or inguinal hernia) and the duration of the operation (in minutes). Biologically, the parameters studied were the mean plasma concentration of endothelin-1 (CmET-1, pico gram/ml or pg/ml) and Vascular Cell Adhesion Molecule-1 (CmVCAM-1, pico gram/ml or $\mathrm{pg} / \mathrm{ml}$ ) [55]. The plasma concentrations of the biological markers obtained in the $\mathrm{RA}^{-}$people determined the control values.

\subsubsection{Method for Measuring Hemodynamic Parameters}

During the preoperative period $(\mathrm{H} 0)$ in $\mathrm{RA}^{+}$, a single measure of the parameters was made in the functional exploration room by a multi-parameter monitor

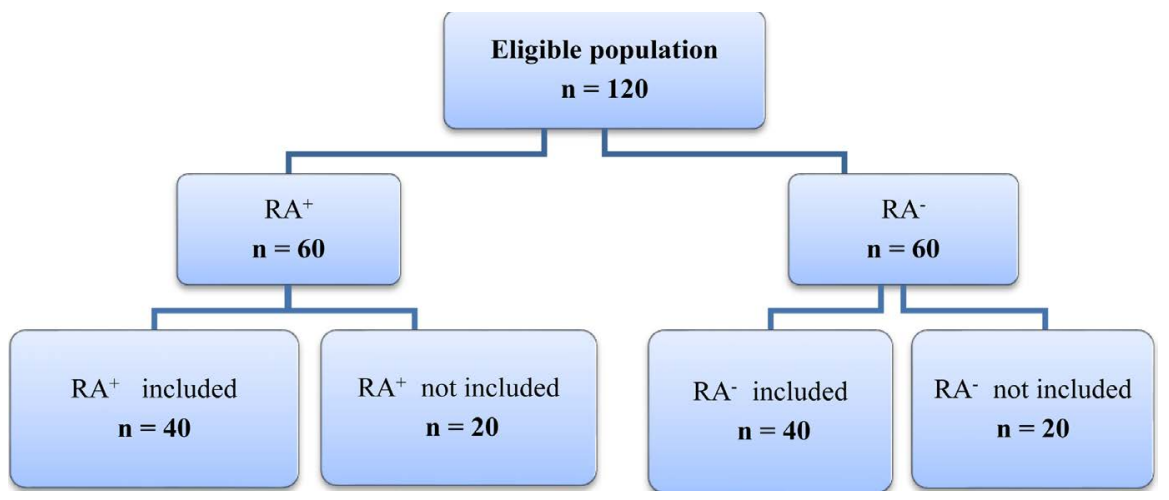

Figure 1. Flow diagram describing the selection of the study population. 
(Philips ${ }^{\circledast}$ IntelliVue MP $40^{\text {ma }}$ Ireland). This measurement was taken immediately after a 15 minute rest period. Intra operatively, it was done at the operating room facility, then every 2 minutes for the first 15 minutes following intrathecal administration of the anesthetic agent. Thereafter, hemodynamic monitoring was continued in the intraoperative and postoperative stages with a measurement interval of 10 minutes. In the controls, the collection of hemodynamic parameters was carried out in the physiological functional exploration room, according to technical procedures similar to those of the patients (multiparametric monitor, Philips IntelliVue MP $40^{\text {tw }}$ Ireland).

\subsubsection{Anesthetic Protocol}

The protocol used during the present investigation was carried out according to that established by previous studies [44]-[49]. Once the patient was installed and monitored, an 18-gauge peripheral venous line (Braun") was put in place., connected to an infusion of isotonic saline $(0.9 \%$ saline, $500 \mathrm{ml})$. The patient was then placed in a seated position. The operator proceeded to locate the L3-L4 inter-vertebral space. The lumbar puncture was performed after strict compliance with asepsis measures by injecting a mixture of $10 \mathrm{mg}$ of Bupivacaine $2.5 \%(\mathrm{Bu}$ pivacaine isobaric and $25 \mu \mathrm{g}$ of fentanyl. The injection was 30 seconds, then, once a dressing was placed at the injection site, the patient was immediately lying supine on the operating table in a tilting position. No prophylactic method of combating hemodynamic changes has been recommended during the $15 \mathrm{mi}$ nutes following SA (vascular filling, administration of vasoconstrictors) [14] [15] [16] [44]-[49], except for hemodynamic variations exceeding the interval retained during the survey.

\subsubsection{Surgical Technic}

After the SA, the patient was previously subjected to the aseptic measures started the day before and early in the morning with a general bath with foaming Povidone iodine (Betadine). The surgical technic used during the present study was that known as Bassini [50] [51] [52] [53].

\subsubsection{Method of Blood Collection and Conditioning}

In the patients, two series of blood samples were taken, the first one hour before the spinal anesthesia, and the second 15 minutes after. In the controls, a single sample was effective. $3 \mathrm{ml}$ of peripheral venous blood was collected in an EDTA tube from an 18-gauge venous catheter $\left(\mathrm{Braun}^{\mathrm{TM}}\right)$. The samples were then sent to the biochemistry laboratory in a cooler $\left(\operatorname{Colman}^{\mathrm{TM}}\right)$, where they were immediately centrifuged (Universal $320^{\text {mim }}$, Hettich Zentrifugen', Germany). The serum was stored in cryotubes (Biologix ${ }^{\mathrm{TM}}$, Biologix Inc. USA) refrigerated at $-86^{\circ} \mathrm{C}$ (Thermo Scientific Forma $900^{\mathrm{TM}}$ Series, Thermo Fisher Scientific Inc.).

\subsubsection{Dosage of ET-1 and VCAM-1}

Endothelin-1 (ET-1) and the Vascular cell adhesion molecule-1 (VCAM-1) were assayed manually by the ELISA technique (Enzyme Linked immunosorbent as- 
say), at the using a Human ET-1 and VCAM-1 ELISA kit ${ }^{\mathrm{TM}}$ (No.E-EL-H0064) kit from Elabscience. The assays were carried out according to the procedure established by the manufacturer [55]. The incubator used was Incucell ${ }^{\circledR}$ brand. Optical density was measured on a Thermo Scientific ${ }^{\oplus}$ brand reader, Multiskan FC. ET-1 and VCAM-1 concentrations were obtained by comparison to a standard range which had been processed along with the samples. The mean concentrations of ET-1 (CmET-1) and VCAM-1 (CmVCAM-1) were expressed in pico gram/ml [55].

\subsubsection{Statistical Methods}

The data, once collected on a survey sheet, was entered into a Microsoft Excel $2013^{\circ}$ file and analyzed using EPI INFO 7.1, SPSS $21^{\circledast}$ software from the Center for Deseases Control (CDC). The descriptive study was carried out by calculating the means, proportions and standard deviations. To compare the proportions, the test used was that of chi-2. The relationships between quantitative and qualitative variables were studied by the Mann-Whitney and Wilcoxon test. Spearman's test was used to study the correlations between plasma concentrations of markers of endothelial dysfunction before and after spinal anesthesia. The threshold of statistical significance set was $5 \%(\mathrm{p}<0.05)$.

\section{Results}

\subsection{Descriptive Study}

\section{Epidemiology Parameters}

The clinical parameters of the study population are summarized in Table 1 . The mean age of the patients was $38.1 \pm 16$ years, and that of the controls $37.5 \pm 15.3$ years $(p=0.865)$. On clinical examination, $72.5 \%$ of patients $(n=29 / 40)$ presented with a simple inguinal hernia, while $32.5 \%(\mathrm{n}=11 / 40)$ had an inguino-scrotal hernia. During the first 15 minutes after spinal anesthesia, 32.5\% of patients $(n=13 / 40)$ had arterial hypotension not exceeding $10 \%$ drop in

Table 1. Epidémiologic parameters.

\begin{tabular}{lcc}
\hline \multicolumn{1}{c}{ Parameters } & Patients & controls \\
\hline Age & & \\
Mean age (year) $\pm \mathrm{SD}$ & $38.1 \pm 16.0$ & $37.5 \pm 15.3$ \\
Pre operative (mmHg) MAP & $92.4 \pm 11.4$ & $90.4 \pm 10.6$ \\
Indications for surgery (n/\%) & $73.6 \pm 11.6$ & $72.5 \pm 10.1$ \\
$\quad$ Inguinal hernias & $29(72.5)$ & $\bullet \mathrm{NT}$ \\
$\quad$ Inguino scrotal hernia & $11(27.5)$ & $\bullet \mathrm{NT}$ \\
Duration of surgery (in min) $\pm \mathrm{SD}$ & $48 \pm 2001$ & $\bullet \mathrm{NT}$ \\
Arterial hypotension (n/\%) & & \\
$\quad$ Yes & $33(82.5)$ & $\bullet \mathrm{NT}$ \\
No & $7(17.5)$ & $\bullet \mathrm{NT}$ \\
\hline
\end{tabular}

- No tested. 
pressure. The mean duration of surgery was $48 \pm 20.1 \mathrm{~min}$, with the extremes of 24 and 130 minutes (Table 1 ).

\subsection{Analytic Study}

\subsubsection{Comparison of Hemodynamic Variables of Patients to Those of Controls}

The MAP obtained in the preoperative period was $92.4 \pm 11.4 \mathrm{mmHg}$ in $\mathrm{RA}^{+}$, against $90.4 \pm 10.6 \mathrm{mmHg}$ in $\mathrm{RA}^{-}(\mathrm{p}=0.422)$. Intraoperatively at $\mathrm{H} 0$, in patients, the MAP was $90.75 \mathrm{mmHg}$, against $81.05 \mathrm{mmHg}$ at $\mathrm{H} 15(\mathrm{p}=0.001)$ and 83.8 $\mathrm{mmHg}$ at $\mathrm{H} 30(\mathrm{p}=0.497)$ (Figure 2). The mean heart rate in the preoperative period was $73.6 \pm 11.6 \mathrm{bpm}$ in the patients, compared with $72.5 \pm 10.1 \mathrm{bpm}$ in the controls $(\mathrm{p}=0.669)$ Figure 2. In the patients, At H15, it was $70.3 \mathrm{bpm}$ and $68.1 \mathrm{bpm}$ at $\mathrm{H} 30(\mathrm{p}=0.004)$.

\subsubsection{Comparison of the Mean Plasma ET-1 (CmET-1) Concentration of Patients to that of Controls before and 15 Minutes after SA}

In controls, CmET- 1 was $1.07 \pm 0.63 \mathrm{pg} / \mathrm{ml}(\mathrm{p}=0.735)$. In patients, it was $1.12 \pm$ $0.56 \mathrm{pg} / \mathrm{ml}$, before the SA, and $1.13 \pm 0.54 \mathrm{pg} / \mathrm{ml} 15$ minutes after $(\mathrm{p}=0.823)$ (Figure 3).

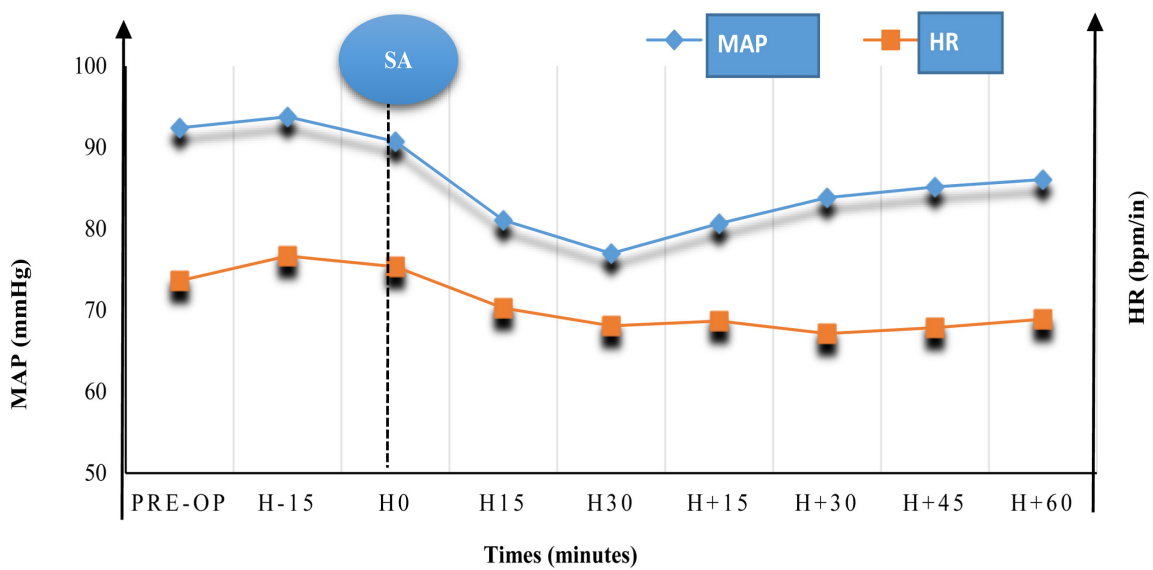

Figure 2. Variations in patients' MAP and heart rate $(\mathrm{HR} / \mathrm{bpm})$ during spinal anesthesia. Legend: PRE-O (Preoperative); H0 (Local anesthetic injection); H15 (15 minutes after the injection); $\mathrm{H}^{+} 15$ (15 minutes after surgery).

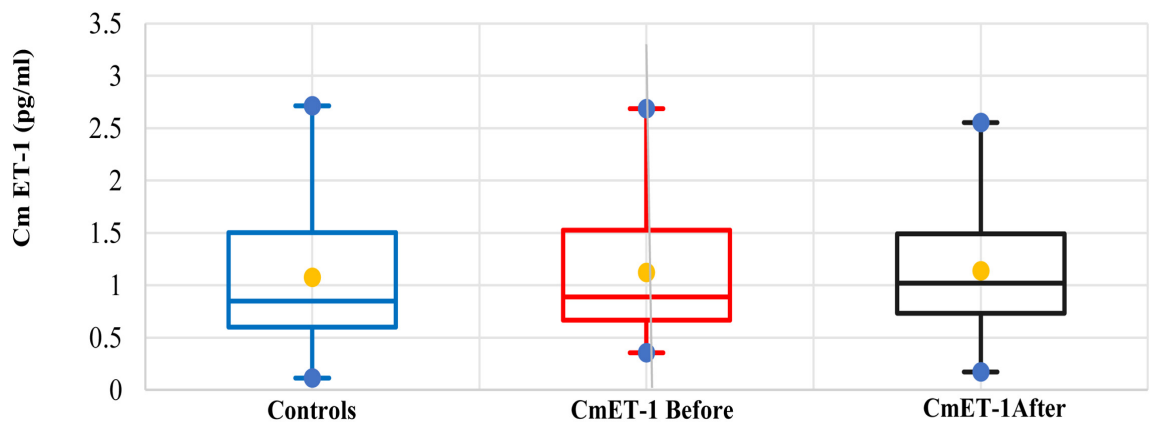

Figure 3. Comparison of mean ET-1 plasma concentrations (CmET-1) of controls to those of patients before and 15 minutes after spinal anesthesia. 


\subsubsection{Comparison of Mean Plasma VCAM-1 (CmVCAM-1) Concentration of Patients vs Controls}

The patients' CmVCAM-1 was $3.57 \pm 0.88 \mathrm{pg} / \mathrm{ml}$ before SA, compared to $3.65 \pm$ $1.04 \mathrm{pg} / \mathrm{ml}$ during the first 15 minutes after SA $(\mathrm{p}=0.257)$. In controls, it was $3.34 \pm 1.56 \mathrm{pg} / \mathrm{ml}(\mathrm{p}=0.862)$ (Figure 4).

\subsubsection{Correlation between Plasma ET-1 Concentration (CmET-1) and Age of the Study Population}

There was no correlation between plasma ET-1 concentration and the age of the study population $(\mathrm{r}=0.155 ; \mathrm{p}=0.171)$ (Figure 5$)$.

\subsubsection{Correlation between the Plasma Concentration of VCAM-1 and the Age of the Study Population}

There was no correlation between the plasma concentration of VCAM- 1 and the age of the study population $(\mathrm{r}=0.058 ; \mathrm{p}=0.610)$ (Figure 6$)$.

\subsubsection{Correlation between Plasma ET-1 Concentration (CmET-1) and MAP in the Study Population}

There was no correlation between plasma ET-1 concentration and MAP in the study population $(\mathrm{r}=0.111 ; \mathrm{p}=0.325)$ (Figure 7$)$.

\subsubsection{Correlation between Plasma Concentrations of ET-1 (CmET-1) and CmVCAM-1 in Controls}

There was a negative correlation between plasma concentrations of ET-1

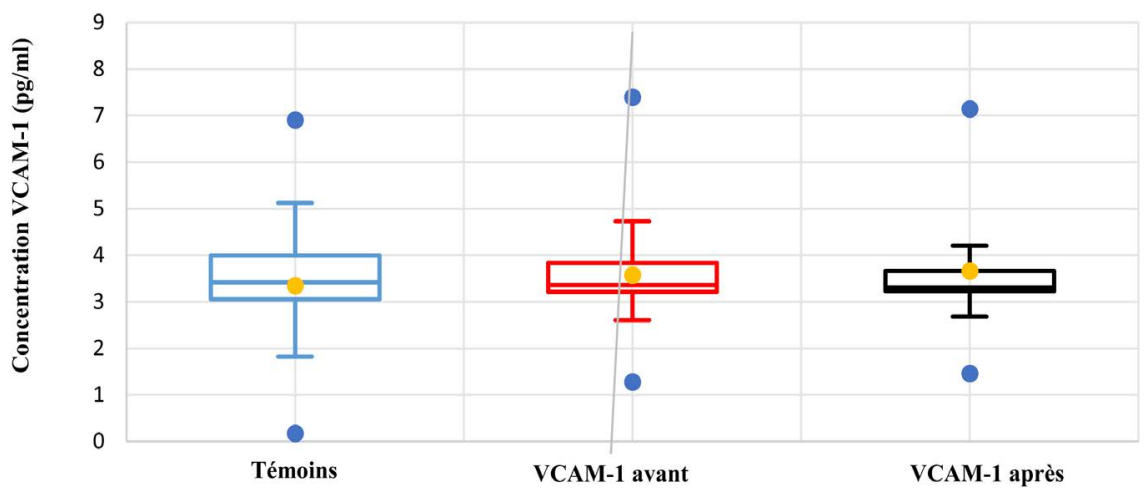

Figure 4. Comparison of mean plasma VCAM-1 concentrations (CmVCAM-1) of controls to those of patients obtained before and 15 minutes after spinal anesthesia.

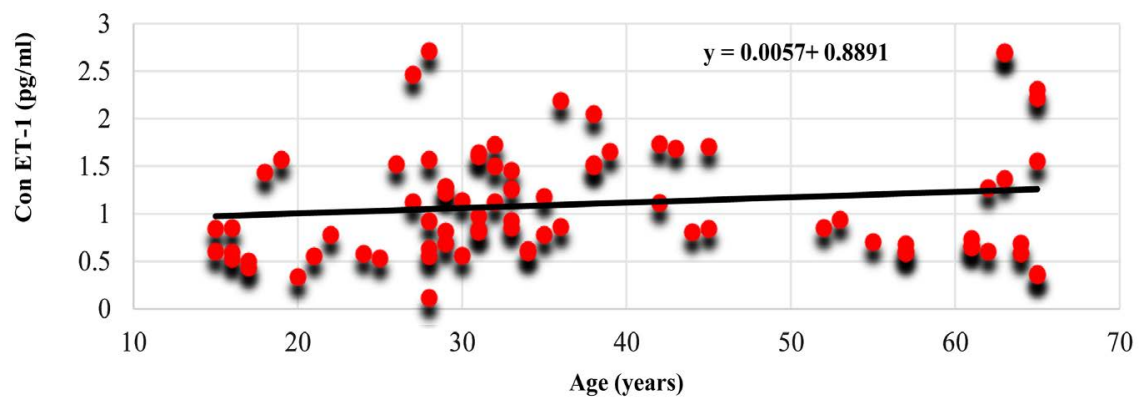

Figure 5. Correlation line between plasma ET-1 concentration (CmET-1) and age of the study population. 


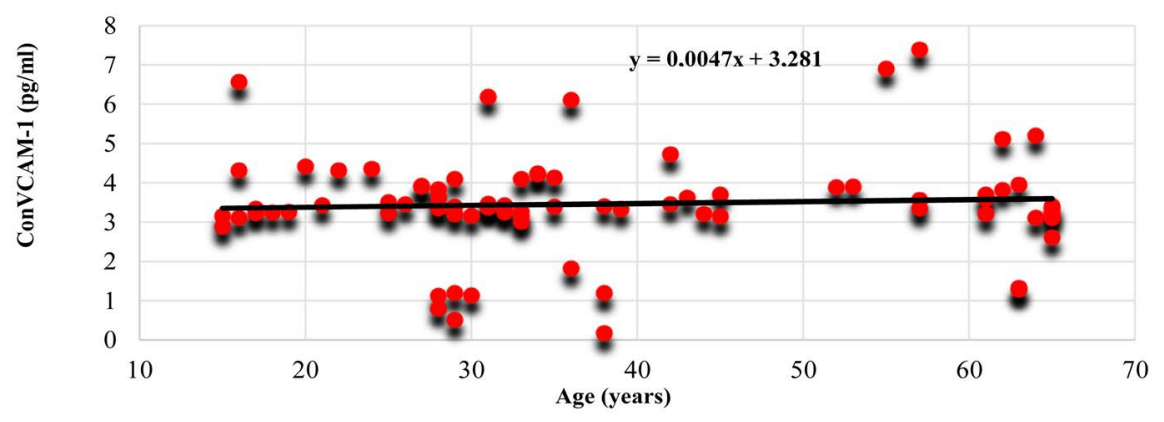

Figure 6. Correlation line between the plasma concentration of VCAM-1 (CmVCAM-1) and the age of the study population.

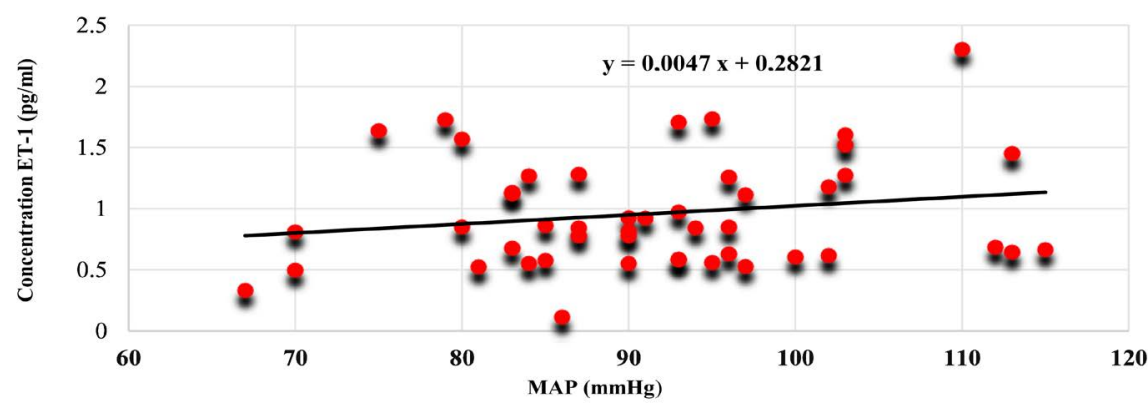

Figure 7. Correlation line between plasma ET-1 concentration and MAP in the study population $(\mathrm{r}=0.111 ; \mathrm{p}=0.325)$ (Figure 7$)$.

$(\mathrm{CmET}-1)$ and VCAM-1 (CmVCAM-1) in controls $(\mathrm{r}=-0.438 ; \mathrm{p}=0.005)$ (Figure 8).

\subsubsection{Correlation between Plasma Concentrations of ET-1 (CmET-1)} and VCAM-1 (CmVCAM-1) in Patients before Spinal Anesthesia

In patients, there was no correlation between plasma concentrations of ET-1 and VCAM-1 before spinal anesthesia $(r=-0.31 ; \mathrm{p}=0.051)$ (Figure 9).

\subsubsection{Correlation between Plasma Concentrations of ET-1 (CmET-1) and VCAM-1 (CmVCAM-1) in Patients 15 Minutes after Spinal Anesthesia}

There was no correlation between plasma ET-1 and VCAM-1 concentrations after spinal anesthesia $(r=0.024 ; \mathrm{p}=0.883)$ (Figure 10).

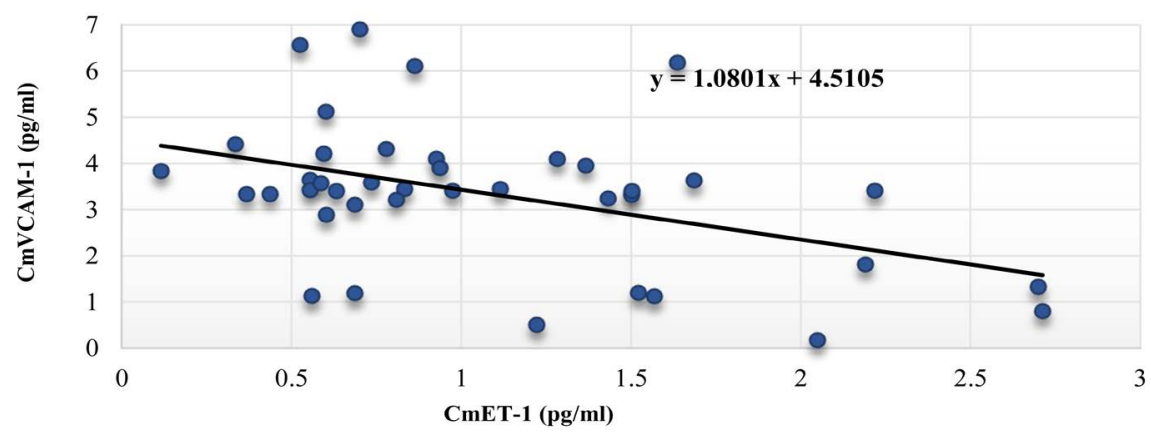

Figure 8. Correlation line between plasma concentrations of ET-1 (CmET-1) and VCAM-1 (CmVCAM-1) in controls. 


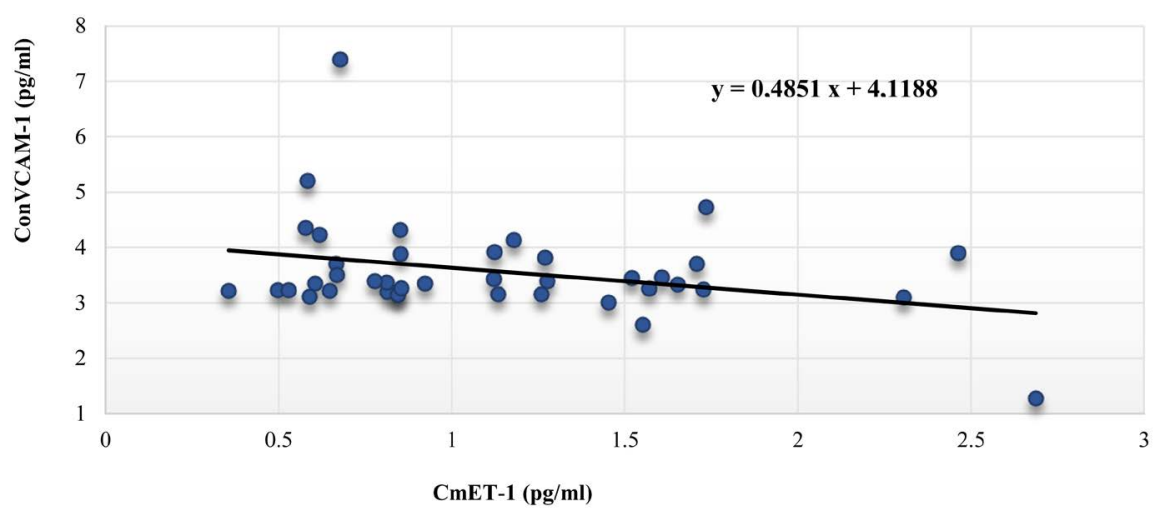

Figure 9. Correlation line between plasma concentrations of ET-1 (CmET-1) and VCAM-1 (CmVCAM-1) in patients before spinal anesthesia.

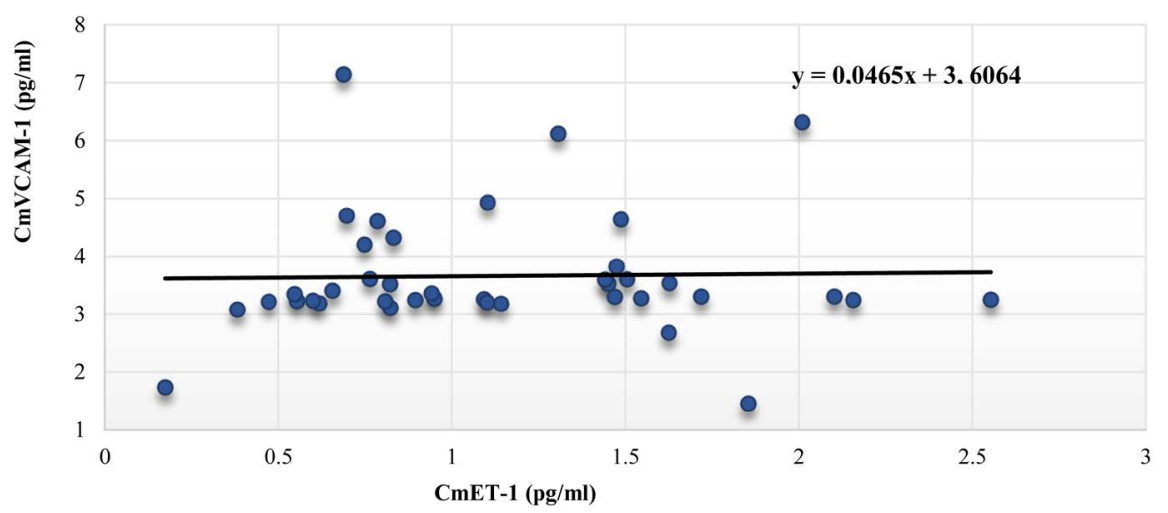

Figure 10. Correlation line between CmET-1 and CmVCAM-1 in patients 15 minutes after spinal anesthesia.

\section{Discussion}

The objective of this work was to determine whether endothelial dysfunction, like sympathetic palsy, was involved in the onset of arterial hypotension observed during the first 15 minutes after spinal anesthesia. To confirm this hypothesis, in people free from any endothelial dysfunction, the correlations between CmET-1, CmVCAM-1, taken from $\mathrm{SA}^{+}$one hour before (H0), then 15 minutes after the SA (H15) and the AMP with heart rate were analyzed $(\mathrm{p}<5 \%)$. During the present investigation, we encountered several constraints, the most important of which were, the refusal to participate $(n=4)$, the arterial hypotension after spine anesthesia requiring hemodynamic support $(n=4)$ and the absence of presentation. On the scheduled day of surgery $(n=6)$. This had an impact on the size of our sample. However, despite these limitations, our data show that the MAP obtained in the preoperative period was $92.4 \pm 11.4 \mathrm{mmHg}$ in the patients, against $90.4 \pm 10.6 \mathrm{mmHg}$ in the controls $(\mathrm{p}=0.422)$. Intra operatively at $\mathrm{H} 0$ in patients, MAP was $90.75 \mathrm{mmHg}$, compared to $81.05 \mathrm{mmHg}$ at $\mathrm{H} 15$ ( $\mathrm{p}=0.001)$. The mean heart rate in the preoperative period was $73.6 \pm 11.6 \mathrm{bpm}$ in the patients, compared to $72.5 \pm 10.1 \mathrm{bpm}$ in the controls $(\mathrm{p}=0.669)$. At H15, it was $70 \mathrm{bpm}$, and $68.1 \mathrm{bpm}$ at $\mathrm{H} 30$ (p = 0.0004). At H0, CmET-1 and CmVCAM-1 of 
$\mathrm{RA}^{-}$were 1.07 and 3.34, respectively, compared to $1.12(\mathrm{p}=0.735)$ and $3.57(\mathrm{p}=$ $0.862)$ in $\mathrm{RA}^{+}$. In $\mathrm{RA}^{+}$, at H15, CmET-1 was 1.13 ( $\mathrm{p}=0.823$ ) and CmVCAM-1 was 3.57 ( $\mathrm{p}=0.257)$. In $\mathrm{RA}^{-}$, a negative correlation existed between CmET-1 and CmVCAM-1 $(\mathrm{r}=-0.438 ; \mathrm{p}=0.005)$. Conversely, in $\mathrm{RA}^{+}$, whether at $\mathrm{H0}(\mathrm{r}=$ $-0.31 ; \mathrm{p}=0.051)$ or at $\mathrm{H} 15(\mathrm{r}=0.024 ; \mathrm{p}=0.883)$, no correlation existed between CmET-1 and CmVCAM-1, nor between MAP and ED markers $(\mathrm{r}=0.111 ; \mathrm{p}=$ 0.325). These results show that there is no relationship between the HPTA which occurs during the first fifteen minutes post SA, CmVCAM-1 and CmET-1.

\subsection{Study Methods}

\subsubsection{Gender}

We did not select women during our survey because the relationship between endothelial dysfunction and sex is complex [56]. A recent literature review found a close relationship between sex, vascular endothelial dysfunction and several endocrine factors [56] [57]. Thus a relationship would exist between on the one hand, the vascular endothelium and hormone receptors in both sexes [56] [57]. On the other hand, other authors find a lot of interference between steroid hormones, the renin angiotensin system and vascular endothelin, especially in women [56] [57]. Indeed, before menopause, steroid hormones would rather play a protective role against cardiovascular risk, in particular metabolicrisk. Conversely, in men, it tends to increase [56] [57]. After menopause, cardiovascular risk increases with age in women, but does not cancel out in males. In all cases, steroid receptors, hormonal cycles, age and gender are believed to be decisive in the occurrence of cardiovascular risk related to ED in women.

\subsubsection{Collection Time}

The sampling time of 15 minutes after spinal anesthesia was chosen because physiologically, the drop in blood pressure occurs approximately three to 5 minutes immediately after injection of the loco regional anesthetic with a maximum peak between the first 15 - 30 minutes [14] [15] [16] [44]-[49]. Moreover, despite the significant frequency of arterial hypotension observed during the first minutes, there is a great variability in the sympathetic response despite the sympathetic paralysis [44]-[49]. Indeed, arterial hypotension is not constant during SA, and would depend on several factors such as the speed of injection, the quantity, the type of anesthetic itself, the position [14] [15] [16] [44]-[49]. This could partly explain the relative frequency of hypotension found during this investigation. Regarding the exact kinetics of endothelial markers, many questions remain as to their production systemically and in situ [33] [34] [36] [37] [38].

\subsubsection{The Choice of Markers for Endothelial Dysfunction}

Endothelial dysfunction is characterized by a modification of the balance between vasodilator, anti-mitotic, anti-thrombogenic and anti-adhesive substances, in favor of those known as vasoconstrictors, pro thrombogenes, pro adhesives 
and proliferatives [7] [8] [9] [19]. Despite the controversies regarding their lower sensitivity compared to non-invasive methods [19] [25] [30] [33] [34] [36]-[42], the choice of ET-1 and VCAM-1 as markers of endothelial dysfunction is due to makes their sensitivities and specificities identical to those of other biomarkers of ED [19]-[25] [30] [33] [34] [36] [40] [41] [42]. Regarding the fact that their dosage is not carried out routinely and therefore without reference values, the recruitment of people free from any pathology made it possible to obtain a control value for these two markers. Regarding our study, the values we obtained are almost similar to those found by Donato et al., during a study carried out on variations in ET-1 concentrations [19] [25] [28]. This sufficiently proves the reproducibility of these two markers.

\subsubsection{Local Anesthetic}

The choice of local anesthetic fell on bupivacaine, as it has been described against ropivacaine, increased cardiovascular toxicity and therefore an effect on the vascular endothelium. This would be related to the voltage dependent sodium channels. Unlike ropivacaine, bupivacaine exhibits more pronounced neurological toxicity, but with equivalent efficacy to bupivacaine [58] [59] [60] [61] [62]. Thus, because of this pronounced cardiovascular effect, we preferred bupivacaine to ropivacaine.

\subsection{Correlations}

\subsubsection{Correlation between the Plasma Concentration of ET-1, VCAM-1 and the Age of the Study Population}

There was no correlation between age and plasma concentrations of ET-1 and VCAM-1. On the Pathophysiological level, aging would lead to an alteration in the endothelial capacity to regulate hemostasis, vascular tone and cell permeability [1]-[7]. This senescence of endothelial cells is associated with a decrease in relaxing factors derived from the endothelium such as nitric oxide (NO), to the detriment of pro-constrictor factors [1]-[7] [23] [24] [25] [26] [27]. However, the increase in the production of NO by human endothelial cells would reduce the expression of ET-1 mRNA, while its decrease amplifies it [1]-[7] [23] [24] [25] [26] [27]. Aging therefore leads to an increase in the plasma concentration of ET-1. With regard to circulating adhesion molecules such as VCAM-1, ICAM-1 and E-selectin, elevated plasma levels of these molecules have been found in the elderly. Thus, aging is a factor influencing the expression and multiplication of these adhesion molecules [1]-[7] [23] [24] [25] [26] [27] [63] [64].

However, these results are different from ours, and could be explained in part by the fairly young average age ( $42.5 \%$ of patients aged 26 - 35 years and $37.5 \%$ of controls). Indeed, in the literature, endothelial dysfunction evolves with the age of the population, life expectancy and therefore aging [63] [64]. Senescence promotes endothelial stress, which activates the inflammatory cascade with the onset of oxidative stress, the consequences of which are first local, then general [63] [64]. Thus, since endothelial dysfunction occurs physiologically only in the 
elderly, we can therefore only observe small variation in these different markers in the young population.

\subsubsection{Correlation between Plasma ET-1 Concentration and MAP in the Study Population}

There was no correlation between ET-1 concentration and MAP in the study population. The mean arterial pressure physiologically reflects the pressure of continuous perfusion of the organs. It depends on systolic and diastolic arterial pressures [65]. Unlike pulse pressure, to date there is very little data explicitly dealing with the relationship between endothelial dysfunction and mean arterial pressure [65] [66]. In this case, this could explain the result obtained and therefore would reflect an absence of direct relationship in physiological situation of markers of endothelial dysfunction and mean arterial pressure. In addition, there is heterogeneity of endothelial cells in the different types of vessels. The mean arterial pressure reflecting the intra capillary pressure, the latter could not be correlated with endothelial dysfunction given the inhomogeneous nature of endothelial cells [67]. Moreover, due to the relatively young average age of the study population, this would partly explain the result obtained. Indeed, aging is the main underlying risk factor for high blood pressure, as long as functional changes in the vascular endothelium occur [65] [66] [67]. This aging of endothelial cells is associated with a decrease in NO synthesis and therefore an increase in the plasma concentration of ET-1 [1]-[9] [17] [18] [19]. Since endothelin-1 is a vasoconstrictor, its increase will also cause an increase in blood pressure.

\subsubsection{Comparison of ET-1 and VCAM-1 Plasma Concentrations of Controls to Those of Patients Obtained before Spinal Anesthesia}

The plasma assay of ET-1 and VCAM-1 in people free from any pathology allowed us to have control values of these two biomarkers of ED. Thus, compared to those of the controls, there was no statistically significant difference between the plasma concentrations of ET- 1 of the controls and those of the patients obtained before spinal anesthesia. As the witnesses were people free from any medical or surgical conditions, this result would therefore mean that the hernia had no effect on vasoconstriction. Indeed, ET-1 is one of the most powerful vasoconstrictors in the body, the levels of which are correlated with the intensity of vasoconstriction [19]-[25] [28] [30] [33] [34] [36] [40] [41] [42]. Likewise, given the fact that the plasma concentrations of VCAM-1 of the controls and those of the patients obtained during the pre-anesthetic period were not significantly different, this result suggests that the hernia, at least uncomplicated, has no influence on the process of adhesion of cells to vessels, at least on a systemic level. Indeed, VCAM-1 is produced during endothelial dysfunction. Its concentration increases during inflammatory processes, allowing monocytes to adhere to the endothelium and then migrate into the intima [33] [34] [35]. This investigation showed that the plasma concentrations of ET-1 and VCAM-1 were not affected by the hernia in this specific case. 


\subsubsection{Comparison of Plasma Concentrations of ET-1 and VCAM-1 Obtained in Patients before and 15 Minutes after Spinal Anesthesia}

In patients, plasma concentrations of ET-1 and VCAM-1 obtained before spinal anesthesia did not differ significantly from those collected 15 minutes after. This result could have several meanings. A first explanation would be that the injection of loco regional anesthetics would have no effect on the vascular endothelial cell. Indeed, like most anesthetics, loco regional anesthetics (ALR) cause vasoplegia leading to vasodilation, one of the mechanisms of which would be paralysis of the lumbar sympathetic nervous system. This state of affairs justifies the administration of a vasoconstrictor agent and vascular filling as a therapy [60] [61] [62] [44]-[49]. However, one question remains. Is the arterial hypotension observed during intrathecal administration of ALRs exclusively related to paralysis of the sympathetic system? Could another mechanism not be related to the diffusion of these drugs to the level of the endothelial cell, when we know that general and especially local anesthetics alter the relaxing function of the vessels [11] [12] [13] [70]. In this case, would this diffusion lead to a direct effect promoting the initiation or amplifying the phenomena of vasodilations observed? Indeed, physical or chemical stimulation of the endothelial cell can lead to a modification of vasomotricity by an increase or a decrease in arterial pressure depending on the mediator released pro or anti vasoconstrictor [1] [2] [6] [7] [8] [9] [19]. The second explanation would relate to the dose. Thus, despite the fact that the effects of loco regional anesthetics on endothelial function are not yet fully understood, the amount of anesthetic injected (10 $\mathrm{mg}$ bupivacaine) was probably insufficient to be able to create significant variations in the various markers of endothelial dysfunction. Indeed, Ben-David et al. demonstrated that he had a less pronounced decrease in blood pressure during spinal anesthesia performed with minidoses of bupivacaine and fentanyl [67]. This hypothesis is supported by the low rate of arterial hypotension $(n=13 / 40$, or $32.5 \%)$ recorded during this study. In addition, during an animal model study carried out by Meyer et al on the effects of ALRs on endothelial dysfunction, a dose-dependent alteration was found in relation to a decrease in the availability of nitric oxide. According to the authors, this would contribute significantly to the reduction of blood flow [68]. In addition, the start of compensation for intraoperative water intake from which patients systematically benefit could also explain the results found. Indeed, during a study concerning the effect of filling with intravenous fluids on the secretion of vasoactive peptides during cesarean section performed under spinal anesthesia, the infusion of colloids led to a slight decrease in the plasma concentration of ET-1 [69]. Thus, a drop in the plasma ET-1 concentration before spinal anesthesia could therefore be responsible for this lack of variation after anesthesia. In addition, the mechanisms of vascular clearance (degradation in situ) or interactions with other vascular proteins could also explain the data obtained [69]. Another significance of our result would be the earliness of the sample after the spinal anesthesia, which was approximately 15 minutes. 
According to our data, the fall in mean arterial pressure took place on average 15 minutes after spinal anesthesia (H15), with an acme around 30 minutes, probably reflecting the action of anesthetic drugs on the vasomotor system. In addition, the time to set up sensory block is reduced by approximately 2 minutes when using doses of Bupivacaine greater than $10 \mathrm{mg}$ [68]. Thus, the assay may have been performed early in order to properly assess the effects of spinal anesthesia on ET-1 and VCAM-1 concentrations. Even if the sensitivity of the biomarkers that we have used is no longer to be demonstrated [17], their specificity remains relatively less good than those of non-invasive methods. Consequently, it could also confirm the lack of correlation found [19] [25] [30] [33] [34] [36]-[42].

\subsubsection{Correlation between Plasma Concentrations of ET-1 and VCAM-1 Obtained in Patients before Spinal Anesthesia and Those in Controls}

There was no correlation between the plasma concentrations of ET-1 and VCAM-1 obtained prior to spinal anesthesia in patients $(\mathrm{r}=-0.31 ; \mathrm{p}=0.051)$. On the other hand, a negative correlation was found between these two markers in the controls $(\mathrm{r}=-0.438 ; \mathrm{p}=0.005)$. This result would mean that vasoconstriction decreases the adhesion of cells to vessels. Conversely, vasodilation would promote it. Thus, under physiological conditions, the secretion of ET-1 would be inversely correlated to that of VCAM-1. Conversely, during pathological states such as sepsis, endothelial cells undergo changes in oxygenation rates and the effects of the many mediators released (reactive oxygen species, cytokines, complement and serum proteases). These results in functional and structural modifications of the endothelium causing an alteration of vascular tone (intense vasoconstriction then vasodilation) but also an increase in cell adhesion (thanks to adhesion molecules) allowing the migration of leukocytes to the inflammatory site. [37] [38]. This situation constitutes a state which allows the body to fight against an inflammatory mechanism.

\subsubsection{Correlation between Plasma Concentrations of ET-1 and VCAM-1 Collected from Patients 15 Minutes after Spinal Anesthesia}

In patients, there was no correlation between plasma concentrations of ET-1 and those of VCAM- 1 collected 15 minutes after spinal anesthesia $(r=0.024 ; p=$ 0.883 ). Indeed, our results show that as the plasma concentrations of ET-1 increased, no changes in the concentrations of VCAM-1 were observed $(r=0.024$; $\mathrm{p}=0.883)$. In this case, this result would mean that after spinal anesthesia, the negative correlation found in this study between ET-1 and VCAM-1 in patients before spinal anesthesia $(\mathrm{r}=-0.31 ; \mathrm{p}=0.051)$ and the controls $(\mathrm{r}=$ $-0.438 ; p=0.005)$ under physiological conditions which reflected an inverse relationship between vasoconstriction and cell adhesion would be modified after spinal anesthesia. This result is similar to that found by two contemporary studies, one carried out on the pulmonary endothelium and the other on that of the aorta [70]. In the first, human microvascular lung endothelial cells were in- 
cubated in the presence varying concentrations of ropivacaine and lidocaine. The effect of these loco regional anesthetics on nitric oxide production, neutrophil adhesion and endothelial barrier disruption were evaluated. At the end of this incubation, the adhesion of neutrophils and the disruption of endothelial monolayers by the intercellular adhesion molecule had been attenuated [70]. The authors hypothesized that loco regional anesthetics attenuate inflammatory signaling by blocking neutrophil adhesion and endothelial hyper permeability. The other had noted a vasoconstrictor effect of ALRs on an aorta lacking endothelium. It should also be noted that the samples taken after spinal anesthesia could have been qualified as early due to the non-variation in the plasma concentrations of the various endothelial markers. So this correlation could have been different. However, for a better interpretation, our results could be subsequently compared in subsequent studies. Another explanation for the lack of correlation between ET-1 and VCAM-1 15 minutes after spinal anesthesia in patients would relate to the nature and dose of the molecule. Indeed, the vasoconstrictor effect of loco regional anesthetics on the vascular endothelium has been observed with the use of ropivacaine, the cardiovascular effects of which are known to be more pronounced compared to the bupivacaine we used [70]. As well, since this effect is dose dependent, the doses of bupivacaine used may not be sufficient to trigger the observed effect. To a lesser degree, the structural and functional heterogeneity of endothelia within tissues could be an additional explanation [23]. Thus, the response to bupivacaine of the endothelium of the vessels of the lower extremities may be different from the ciliary ones at which this observation was made. Finally, sympathetic paralysis, the main effect of which is vasodilation, could mask the vasoconstrictor effect because of its predominance in this context.

\section{Conclusion}

The intra spinal anesthetic injection (LRA) is responsible for sympathetic paralysis causing arterial hypotension (AHPT) and bradycardia. However, as the action of ALR's and the sympathetic response are variable, some authors have suggested a probable endothelial participation in this arterial hypotension. The objective of this work was to determine whether endothelial dysfunction, like sympathetic palsy, was involved in the onset of arterial hypotension observed during the first 15 minutes after spinal anesthesia. To confirm this hypothesis, in people free from any endothelial dysfunction, the correlations between mean plasma concentrations of endothelin-1 (CmET-1, pg/ml), Vascular Cell Adhesion Molecule-1 (CmVCAM-1, pg/ml) taken from $\mathrm{SA}^{+}$one hour before (H0), then 15 minutes after the SA (H15), and the mean arterial pressure (MAP, $\mathrm{mmHg})$ with heart rate $(\mathrm{bpm})$ were analyzed $(\mathrm{p}<5 \%)$. These results show that there is no relationship between the AHPT which occurs during the first fifteen minutes post SA, CmVCAM-1 and CmET-1. Moreover, these data suggest that ED is not involved in AHPT post SA. 


\section{Conflicts of Interest}

The authors declare no conflicts of interest regarding the publication of this paper.

\section{References}

[1] Su, J.B. (2015) Vascular Endothelial Dysfunction and Pharmacological Treatment. World Journal of Cardiology, 7, 719-741. http://dx.doi.org/10.4330/wjc.v7.i11.719

[2] Mahé, G. and Boulon, C. (2016) Chapitre 13-Étude de la Fonction Endothéliale. In: Société Française de Médecine Vasculaire, Collège des Enseignants de Médecine Vasculaire and Collège Français de Pathologie Vasculaire, Eds., Maladies Artérielles, Elsevier Masson SAS, Paris, 157-160. https://doi.org/10.1016/B978-2-294-74970-4.00020-8

[3] Lund, A.K. (2018) Oxidants and Endothelial Dysfunction. In: McQueen, C.A., Ed., Comprehensive Toxicology, Vol. 13, Elsevier Science, Amstedam, 252-281. https://doi.org/10.1016/B978-0-12-801238-3.65250-9

[4] Devito, F., Zito, A., Dragonieri, S., Carratù, P., Quaranta, V.N., et al. (2017) Evaluation of Endothelial Function and Cardiovascular Risk in Non-Obese Patients with Slight Degree of Obstructive Sleep Apnea Syndrome. Monaldi Archives for Chest Disease, 87, 39-46. https://doi.org/10.4081/monaldi.2017.822

[5] Gimbrone, M.A. and Guillermo, G.-C. (2016) Endothelial Cell Dysfunction and the Pathobiology of Atherosclerosis. Circulation Research, 118, 620-636. https://doi.org/10.1161/CIRCRESAHA.115.306301

[6] Rajendran, P., Rengarajan, T., Thangavel, J., Nishigaki, Y., Sakthisekaran, D., Sethi, G., et al. (2013) The Vascular Endothelium and Human Diseases. International Journal of Biological Sciences, 9, 1057-1069. https://doi.org/10.7150/ijbs.7502

[7] Schini-Kerth, V. (2012) Endothelial Dysfunction: Characterization, Mechanisms Involved and Potential Consequences on Vascular Function. Journal of Vascular Diseases, 37, $39 \mathrm{p}$.

[8] Harvey, A., Montezano, A.C., Lopes, R.A., Rios, F. and Touyz, R.M. (2016) Vascular Fibrosis in Aging and Hypertension: Molecular Mechanisms and Clinical Implications. The Canadian Journal of Cardiology, 32, 659-668. https://doi.org/10.1016/j.cjca.2016.02.070

[9] Puissant, C., Abraham, P., Durand, S., Humeau-Heurtier, A., Faure, S., Rousseau, P. and Mahé, G. (2014) Endothelial Function: Role, Assessment and Limit. Journal of Vascular Diseases, 39, 47-56. https://doi.org/10.1016/j.jmv.2013.11.004

[10] Budic, I., Pavlovic, D., Kocic, G., Cvetkovic, T., Simic, D., et al. (2011) Biomarkers of Oxidative Stress and Endothelial Dysfunction after Tourniquet Release in Children. Physiological Research, 60, S137-S145. https://doi.org/10.33549/physiolres.932170

[11] Honca, M., Purtuloglu, T., Ozgur Akgul, E., Oztosun, M., Honca, T., et al. (2014) Effects of General and Spinal Anesthetic Techniques on Endothelial Adhesion Molecules in Cesarean Section. Korean Journal of Anesthesiology, 66, 364-370. https://doi.org/10.4097/kjae.2014.66.5.364

[12] Polat, N., Selim Ozkan, A., Gunduz, A., Betul Ulucan, P., Colak, C., et al. (2017) The Effect of Sevoflurane Anesthesia on the Corneal Endothel. Journal of Turgut Ozal Medical Center, 24, 261-264. https://doi.org/10.5455/jtomc.2017.01.017

[13] Piegeler, T., Votta-Velis, E.G., Bakhshi, F.R., Mao Mao, M.S., Carnegie, G., et al. (2014) Endothelial Barrier Protection by Local Anesthetics: Ropivacaine and Lido- 
caine Block Tumor Necrosis Factor- $\alpha$-Induced Endothelial Cell Src Activation Anesthesiology, 120, 1414-1428. https://doi.org/10.1097/ALN.0000000000000174

[14] Aveline, C. (2013) Spinal Anesthesia. Essential. French Society of Anesthesia and Resuscitation, Paris, $57 \mathrm{p}$.

[15] Cureti, S., Anselmi, L., Minotti, B., Franceschini, D., Aquire, J., et al. (2018) Prevention of Arterial Hypotension after Spinal Anesthesia Using Vena Cava Ultrasound to Guide Fluid Management. British Journal of Anesthesia, 120, 101-108. https://doi.org/10.1016/j.bja.2017.08.001

[16] Ferré, F., Martin, C., Bosch, L., Kurrek, M. and Lairez, O. (2020) Control of Spinal Anesthesia-Induced Hypotension in Adults. Local and Regional Anesthesia, 13, 39-46. https://doi.org/10.2147/LRA.S240753

[17] Ibrahim, N.E., Shrestha, S., McCarthy, C., Lyass, C., Li, Y., et al. (2018) Endothelin-1 Predicts Incident Heart Failure, Incident Myocardial Infarction, Cardiovascular Mortality, and All-Cause Mortality in Patients Undergoing Diagnostic Coronary Angiography. Results from the Catheter Sampled Blood Archive in Cardiovascular Diseases (Casablanca) Study. Journal of Americaine College of Cardiology, 71, A773. https://doi.org/10.1016/S0735-1097(18)31314-7

[18] Lu, Y.P., Hasan, A.A., Zeng, S. and Hocher, B. (2017) Plasme ET-1 Cencentrations Are Elevated in Pregnant Women with Hypertension, Meta-Analysis of Clinical Studies. Kidney and Blood Pressure Research, 42, 654-663. https://doi.org/10.1159/000482004

[19] Jankowska-Lech, I., Terelak-Borys, B., Liberek, I. and Wolinska-Witort, E. (2015) Decreased Endothelin-1 Plasma Levels in Multiple Sclerosis Patients: A Possible Factor of Vascular Dysregulation. Medical Science Monitor, 21, 1066-1071. https://doi.org/10.12659/MSM.890899

[20] Flammer, A.J., Anderson, T., Celermajer, D.S., Creager, M.A., Deanfield, J., Ganz, P., et al. (2012) The Assessment of Endothelial Function: From Research into Clinical Practice. Circulation, 126, 753-767. https://doi.org/10.1161/CIRCULATIONAHA.112.093245

[21] Lekakis, J., Abraham, P. and Balbarini, A., Blann, A., Boulanger, C.M., Cockcroft, J., et al. (2011) Methods for Evaluating Endothelial Function: A Position Statement from the European Society of Cardiology Working Group on Peripheral Circulation. European Journal of Preventive Cardiology, 18, 775-789. https://doi.org/10.1177/1741826711398179

[22] Malakul, W., Pengnet, S., Kumchoom, C. and Tunsophon, S. (2018) Naringin Ameliorates Endothelial Dysfunction in Fructose-Fed Rats. Experimental and Therapeutic Medicine, 15, 3140-3146. https://doi.org/10.3892/etm.2018.5759

[23] Ait Oufella, H., Maury, E., Guidet, B. and Offenstadt, G. (2008) L’Endothélium. Un nouvel Organ. Réanimation, 17, 126-136.

https://doi.org/10.1016/j.reaurg.2007.12.005

[24] Haberzettl, P., Conklin, D.J., Abplanalp, W.T., Bhatnagar, A. and O’Toole, T.E. (2018) Inhalation of Fine Particulate Matter Impars Endothelial Progenitor Cell Function via Pulmonary Oxidative Stress. Arteriosclerosis, Thrombosis, and Vascular Biology, 38, 131-142. https://doi.org/10.1161/ATVBAHA.117.309971

[25] Donato, A.J., Morgan, R.G., Walker, A.E. and Lesniewsky, L.A. (2015) Cellular and Molecular Biology of Endothelilal Cell Aging. Journal of Molecular and Cellular Cardiology, 89, 122-135. https://doi.org/10.1016/j.yjmcc.2015.01.021

[26] Cheng, Z., Jiang, X., Kruger, W.D., Praticò, D., Gupta, S., Mallilankaraman, K., et al. (2011) Hyperhomocysteinemia Impairs Endothelium-Derived Hyperpolarizing Fac- 
tor-Mediated Vasorelaxation in Transgenic Cystathionine Beta Synthase-Deficient Mice. Blood, 118, 1998-2006.

[27] Cassuto, J., Dou, H., Czikora, I., Szabo, A., Patel, V.S., Kamath, V., et al. (2014) Peroxynitrite Disrupts Endothelial Caveolae Leading to eNOS Uncoupling and Diminished Flow-Mediated Dilation in Coronary Arterioles of Diabetic Patients. Diabetes, 63, 1381-1393. https://doi.org/10.2337/db13-0577

[28] Yoshino, O., Yamada-Nomoto, K., Kobayashi, M., Andoh, T., Hongo, M., Ono, Y., et al. (2018) Bradykinin System Is Involved in Endometriosis-Related Pain through Endothelin-1 Production. European Journal of Pain, 22, 501-510. https://doi.org/10.1002/ejp.1133

[29] Virdis, A. and Taddei, S. (2011) How to Evaluate Microvascular Organ Domage in Hypertension. High Blood Pressure and Cardiovascular Prevention, 18, 163-167. https://doi.org/10.2165/11593630-000000000-00000

[30] Yoganandamoorthy, S., Munasinghe, M.A.D.S.N., Wanigasuriya, L.V.U., Priyankara, M.K.K. and Jayasinghe, S. (2020) Non-Invasive Assessment of Endothelial Dysfunction: A Novel Method to Predict Severe COVID-19? Medical Hypotheses, 144, Article ID: 110229. https://doi.org/10.1016/j.mehy.2020.110229

[31] Pons, S., Fodil, S., Azoulay, E. and Zafrani, L. (2020) The Vascular Endothelium: The Cornerstone of Organ Dysfunction in Severe SARS-CoV-2 Infection. Critical Caree, 24, Article No. 353. https://doi.org/10.1186/s13054-020-03062-7

[32] Amraei, R. and Rahimi, N. (2020) COVID-19 Renin-Angiotensin System and Endothelial Dysfunction. Cells, 9, 1652. https://doi.org/10.3390/cells9071652

[33] De Lorenzo, A., Escobar, S. and Tibiriçá, E. (2020) Systemic Endothelial Dysfunction: A Common Pathway for COVID-19, Cardiovascular and Metabolic Diseases. Nutrition, Metabolism \& Cardiovascular Diseases, 30, 1401-1402. https://doi.org/10.1016/j.numecd.2020.05.007

[34] Arrebola-Moreno, A.L., Laclaustra, M. and Kaski, J.C. (2012) Noninvasive Assessment of Endothelial Function in Clinical Practice. Revista Española de Cardiología, 65, 80-90. https://doi.org/10.1016/j.recesp.2011.09.012

[35] Froldi, G. and Dorigo, P. (2020) Endothelial Dysfunction in Coronavirus Disease 2019 (COVID-19): Gender and Age Influences. Medical Hypotheses, 144, Article ID: 110015. https://doi.org/10.1016/j.mehy.2020.110015

[36] Sena, C.M., Pereira, A.M. and Seiça, R. (2013) Endothelial Dysfunction-A Major Mediator of Diabetic Vascular Disease. Biochimica et Biophysica Acta (BBA)Molecular Basis of Disease, 1832, 2216-2231. https://doi.org/10.1016/j.bbadis.2013.08.006

[37] Zhong, L., Simard, M.J. and Huot, J. (2018) Endothelial microRNAs Regulating the NF-kB Pathway and Adhesion Cell Molecule during Inflammation. FASEB Journal, 32, 4070-4084. https://doi.org/10.1096/fj.201701536R

[38] Skibsted, S., Jones, A.E., Puskarich, M.A., Arnold, R., Sherwin, R., Stephen, T., et al. (2013) Biomarkers of Endothelial Cell Activation in Early Sepsis. SHOCK, 39, 427-432. https://doi.org/10.1097/SHK.0b013e3182903f0d

[39] Ruediger, C.D., John, B., Kumar, S., Lim, H.S., Rangnekar, G., Roberts-Thomson, K.C., et al. (2018) Influence of Ethnic Background on Left Atrial Markers of Inflammation, Endothelial Function and Tissue Remodelling. Indian Pacing and Electrophysiology Journal, 18, 1-5. https://doi.org/10.1016/j.ipej.2017.08.002

[40] Puissant, C., Abraham, P., Durand, S., Humeau-Heurtier, A., Leftheriotis, G., Mahe, G. (2013) Reproductibilité de l'Evaluation de la fonction Endothéliale Cutanée par Méthode Laser Mono-Point et Laser Speckle Chez l'homme. Journal des Maladies 
Vasculaires, 38, 310-311. https://doi.org/10.1016/j.jmv.2013.07.046

[41] Mahe, G., Humeau-Heurtier, A., Durand, S., Leftheriotis, G. and Abraham, P. (2012) Assessment of Skin Microvascular Function and Dysfunction with Laser Speckle Contrast Imaging. Circulation: Cardiovascular Imaging, 5, 155-1563. https://doi.org/10.1161/CIRCIMAGING.111.970418

[42] Humeau-Heurtier, A., Guerreschi, E., Abraham, P. and Mahe, G. (2013) Relevance of Laser Doppler and Laser Speckle Techniques for Assessing Vascular Function: State of the Art and Future Trends. IEEE Transactions on Biomedical Engineering, 60, 659-666. https://doi.org/10.1109/TBME.2013.2243449

[43] World Medical Association (2013) Declaration of Helsinki: Ethical Principles for Medical Research Involving Human Subjects. JAMA, 310, 2191-2194.

[44] Beecroft, C.L. (2015) Spinal Anesthesia. Anesthesia and Intensive Care Medicine, 16, 563-565. https://doi.org/10.1016/j.mpaic.2015.08.001

[45] Luna, C.A., Tulcán-Toro, R., Romero, F. and Luna, M.F. (2017) Measurement of Residual Volume in Spinal Needles after Spinal Anesthesia. Colombian Journal of Anesthesiology, 45, 12-15. https://doi.org/10.1016/j.rcae.2017.08.013

[46] Afane Ela, A., Ngayap, G., Owono Etoundi, P., Essiene, A., Bengono, R. and Mikone, A. (2013) Rachianesthésie chez l'Enfant. Bilan d'une Année d'Expérience à l'Hôpital Central de Yaoundé. Health Sciences and Disease, 14, 1-5.

[47] Rutschmann, B. and Albrecht, E. (2015) Anesthésiques Locaux. In: Albrecht, É., Ed., Manuel Pratique d'Anesthésie, Elsevier Masson, Paris, 153-161.

https://doi.org/10.1016/B978-2-294-73189-1.00012-X

[48] Bennasr, L., Ben Marzouk, S., Boussaidi, I., Attia, H., Shili, A., Zohd, J., et al. (2015) Prévention de l'Hypotension Induite par la Rachianesthésie au cours de la Césarienne Programmée: Ondansétron versus Placébo. Anesthésie \& Réanimation, 1, A148-A149. https://doi.org/10.1016/j.anrea.2015.07.230

[49] Hasanin, A., Mokhtar, A.M., Badawi, A.A. and Fouad, R. (2017) Hypotension Anesthésie Post-Spinale lors de la Cesarienne. Journal Egyptien d'Anesthésie, 33, 189-193. https://doi.org/10.1016/j.egja.2017.03.003

[50] Rosenberg, J. and Andresen, K. (2016) The Onstep Method for Inguinal Hernia Repair: Operative Technique and Technical Tips. Surgery Research and Practice, 2016, Article ID: 6935167. https://doi.org/10.1155/2016/6935167

[51] Garrett, M. (2017) Bassini Repair of Inguinal Hernia. In: Hoballah, J., Scott-Conner C. and Chong, H., Eds., Operative Dictations in General and Vascular Surgery, Springer, Cham, 419-421. https://doi.org/10.1007/978-3-319-44797-1 122

[52] Koutora, B., Alassani, F., Amouzou, E., Sakiye, A. and Fayissal Geraldo, R. (2019) Prise en Charge des Hernies de l'aine: Expérience d'un Hôpital Confessionnel en Zone Rurale au Togo. European Scientific Journal, 15, 191-201.

[53] Gorad, K.P., Tonape, T., Patil, S., Gautam, R. and Lohar, R. (2013) Modified Bassini's Repair: Our Experience in a Rural Hospital Setup. Medical Journal of Dr. D.Y. Patil Vidyapeeth, 6, 378-380. https://doi.org/10.4103/0975-2870.118276

[54] Ma, Y., Liu, Y., Xu, J., Wang, Y., Du, F. and Wang, Y. (2019) The Influence of Mean Arterial Pressure on the Efficacy and Safety of Dual Antiplatelet Therapy in Minor Stroke or Transient Ischemic Attack Patients. The Journal of Clinical Hypertension, 21, 598-604. https://doi.org/10.1111/jch.13527

[55] Elabscience (2020) Consulted the 18 Janvier 2020. http://www.elabscience.com//index.php/product/view/

[56] Stanhewicz, A.E., Wenner, M.M. and Stachenfeld, S.N. (2018) Sex Differences in 
Endothelial Function Important to Vascular Health and Overall Cardiovascular Disease Risk Across the Lifespan. American Journal of Physiology-Heart and Circulatory Physiology, 315, H1569-H1588. https://doi.org/10.1152/ajpheart.00396.2018

[57] Davel, A.P., Lu, Q., Moss, M.E., Rao, S., Anwar, I.J., DuPont, J.J., et al. (2018) Sex-Specific Mechanisms of Resistance Vessel Endothelial Dysfunction Induced by Cardiometabolic Risk Factors. Journal of the American Heart Association, 7, e007675.

[58] Daisy, T. and Wong, G.A. (2009) Drug Interactions. Lipoxygenase Inhibitors Interfere with Ropivacaine-Induced Vasoconstriction. Canadian Journal of Anesthesia, 56, 279-283. https://doi.org/10.1007/s12630-009-9062-5

[59] Leleu, V., Ntouba, A., Laigle, C., Lorne, E. and Dupont, H. (2015) Comparaison de l'Efficacité de la lévobupivacaine $0.5 \%$ et de la Ropivacaine $0.5 \%$ Administrées par voie Intratéchale. Etude Prospective Randomisée. Anesthésie \& Réanimation, 1, A142. https://doi.org/10.1016/j.anrea.2015.07.220

[60] Olapour, A., Akhondzadeh, R., Rashidi, M., Gousheh, M. and Homayoon, R. (2020) Comparing the Effect of Bupivacaine and Ropivacaine in Cesarean Delivery with Spinal Anesthesia. Anesthesia and Pain Medicine, 10, Article ID: e94155. https://dx.doi.org/10.5812/aapm.94155

[61] Ramírez Villagómez, J.A., Pappalardo, L., et al. (2020) Efficacy and Safety of the Combination of Bupivacaine and Fentanyl in Spinal Anesthesia. Journal of Anesthesia and Intensive Care Medicine, 10, Article ID: 555790.

[62] Mansour, N.A., AL-Belasy, F.A.-M., Abdel-Monem Tawfik, M. and Marzook, H.A, (2012) Ropivacaine versus Bupivacaine in Postoperative Pain Control. Journal of Biotechnology and Biomaterials, 2, 137. https://doi.org/10.4172/2155-952X.1000137

[63] Donato, A.J., Machin, D.R. and Lesniewski, L.A. (2018) Mechanisms of Dysfunction in the Aging Vasculature and Role in Age-Related Disease. Circulation Research, 123, 825-848. https://doi.org/10.1161/CIRCRESAHA.118.312563

[64] Sepúlveda, C., Palomo, I. and Fuentes, E. (2017) Mechanisms of Endothelial Dysfunction during Aging: Predisposition to Thrombosis. Mechanisms of Ageing and Development, 164, 91-99. https://doi.org/10.1016/j.mad.2017.04.011

[65] Vedel, A.G., Holmgaard, F., Rasmussen, L.S., Paulson, O.B., Thomsen, C. and Danielsen, E.R. (2016) Perfusion Pressure Cerebral Infarct (PPCI) Trial-The Importance of Mean Arterial Pressure during Cardiopulmonary Bypass to Prevent Cerebral Complications after Cardiac Surgery: Study Protocol for a Randomised Controlled Trial. Trials, 17, Article No. 247. https://doi.org/10.1186/s13063-016-1373-6

[66] Harvey, A., Montezano, A.C. and Touyz, R.M. (2015) Vascular Biology of Aging-Implications in Hypertension. Journal of Molecular and Cellular Cardiology, 83, 112-121. https://doi.org/10.1016/j.yjmcc.2015.04.011

[67] Ben-David, B., Frankel, R., Arzumonov, T., Marchevsky, Y. and Volpin, G. (2000) Minidose Bupivacaine-Fentanyl Spinal Anesthesia for Surgical Repair of Hip Fracture in the Aged. Anesthesiology, 92, 6-10. https://doi.org/10.1097/00000542-200001000-00007

[68] Meyer, P., Flammer, J. and Luscher, T.F. (1993) Local Anesthetic Drugs Reduce Endothelium-Dependent Relaxations of Porcine Ciliary Arteries. Investigative Ophthalmology and Visual Science, 34, 2730-2736.

[69] Pouta, A.M., Karinen, J., Vuolteenaho, J.O. and Laatikainen, T.J. (1996) Effect of Intravenous Fluid Preload on Vasoactive Peptide Secretion during Caesarean Sec- 
tion under Spinal Anaesthesia. Anaesthesia, 51, 128-132.

https://doi.org/10.1111/j.1365-2044.1996.tb07698.x

[70] Piegeler, T., Dull, R.O., Hu, G.C., Castellon, M., et al. (2014) Ropivacaine Attenuates Endotoxin plus Hyperinflation-Mediated Acute Lung Injury via Inhibition of Early-Onset Src-Dependent Signaling. BMC Anesthesiology, 14, 57.

https://doi.org/10.1186/1471-2253-14-57 